\title{
DEGENERALIZING INSTRUMENT APPROACH MINIMA TO NON INSTRUMENT RUNWAYS: A CASE STUDY FOR PAYERNE AIRPORT IN SWITZERLAND
}

\author{
Thomas DAUTERMANN (D), Thomas LUDWIG \\ Institute of Flight Guidance, German Aerospace Center (DLR), Braunschweig, Germany
}

Received 18 March 2019; accepted 18 December 2019

\begin{abstract}
Instrument approaches to non- instrument runways were made possible by the new approach classification of ICAO. As a conservative solution, the procedure design guidelines by the national civil aviation authorities apply circling minima to those approaches to non-instrument runways. However, the classification as non-instrument runway is very binary. Often a small item causes a reduction from instrument to a non-instrument runway and the circling minima become thus very conservative. Here, two cases are shown, Payerne, a non-instrument runway, and Ouessant with an instrument runway, both equipped very differently but both serving Instrument Flight Rules (IFR) traffic. Solutions for Payerne and other similarly highly equipped non-instrument runways are proposed in order to be able to accommodate at least non-precision minima.
\end{abstract}

Keywords: non instrument runway, instrument approach, SESAR, landing minima, aerodrome, combined vision system.

\section{Introduction}

Since the approach classification amendment to Annex 6 of the International Civil Aviation Organization (ICAO) Meeting of Chicago triggered by state letter AN 11/1.1-12/40 CITE, instrument approaches to Non Instrument Runways (NIR) have become ICAO compliant and can thus be realized by the member states without undue difficulties. The state letter indicates in its Figure 1-A (ICAO, 2012b) that approaches of type A with 2D and 3D guidance are possible down to a minimum descent height or decision height of $250 \mathrm{ft}(76.2 \mathrm{~m})$ above the runway threshold. Subsequently, change became effective in 2016 with the scheduled amendment cycle. Mainly, this change was triggered by transition from conventional navigation aid based infrastructure to Performance Based Navigation (ICAO, 2012a). Now instrument approach operations are classified on the guidance they provide rather than by the type of navigation sensor that they are based on. One has to note, however, that there is a clear distinction between operations and procedures and the new classification concerns operations. Procedures are used to specify navigation guidance to reach the runway end while the operation definition is more concerned with a holistic view of the approach process. In other words, the procedure is a part of the operation which provides the pilot with guidance and situational awareness.
This possibility to conduct instrument operations to NIR has the potential to enhance access to many general aviation airfields by establishing cost effective PBN procedures with the appropriate visibility and cloud base for such an operation. An overview of the regulatory framework, requirements for on-site personnel and the potential number of new, instrument accessible runways is given in European GNSS Agency and ESSP (2017). The civil aviation authority of the United Kingdom already issued guidelines and a safety case for "Application for instrument approach procedures to aerodromes without an instrument runway and/or approach control" (United Kingdom Civil Aviation Authority, 2014). The Swiss federal office of civil aviation also published guidelines for an "IFR Approach Minimum on Non-Instrument Runways" (Swiss Federal Office of Civil Aviation, 2009)

For each instrument approach, ICAO Document 6186 (2014) allows the publication of circling minima. Here, an approach is conducted to a specific runway or approach point. When reaching visual conditions on the approach at or above the prescribed circling minima, the aircraft flies a visual pattern and lands in the direction opposite to the approach. This is useful, in particular when airports only have one instrument approach to one runway end, but the winds favor a landing from the other directions. Since the circling is performed visually, the general approach used

${ }^{*}$ Corresponding author. E-mail: thomas.dautermann@dlr.de 
by procedure designers when publishing an instrument procedure to a NIR is to apply circling minima or higher for all aircraft categories. For a typical business aircraft of the approach category $\mathrm{B}$, this would be an minimum descent height of $500 \mathrm{ft}$ (rounded up from $150 \mathrm{~m}=492 \mathrm{ft}$, PANS-OPS Table I-4-7-3) and a visibility of 1600 meters. For other categories see ICAO (2014).

\section{ICAO Annex 14 instrument runway definition}

ICAO lays out the requirements for aerodromes in Annex 14 to the conventions of Chicago (ICAO, 2016). Among other things it also classifies airport runways into instrument runways and NIR, the latter being intended for Visual Flight Rules (VFR) or visual approach operations. Since an instrument runway has to fulfil very specific requirements, a non- instrument runway can range from a simple grass strip to one fulfilling almost all requirements of an instrument one but not all of them. Here, the minimum requirements for an instrument runway are collected in order to better understand the runway classification. ICAO identifies runways by code numbers based on their length of take-off distance available. Code number 1 is for runways of less than $800 \mathrm{~m}$ length, code number 2 from $800 \mathrm{~m}$ to $1200 \mathrm{~m}$, code number 3 from $800 \mathrm{~m}$ to $1800 \mathrm{~m}$ and code number 4 is for runways longer than $1800 \mathrm{~m}$. This is combined with a code letter for maximum wing span and main wheels track allowed, i.e. code letter $C$ for a wingspan over $24 \mathrm{~m}$ less than $<36 \mathrm{~m}$ and main wheels track of more than $6 \mathrm{~m}$ but less than $9 \mathrm{~m}$ (Classification from Table 1-1, ICAO, 2016).

In terms of physical characteristics, an instrument runway must have a runway strip extending at least $60 \mathrm{~m}$ before the threshold and beyond the runway or stop way end (Annex 14, Section 3.4.2 ICAO, 2016) and laterally at least $150 \mathrm{~m}$ for code $3 / 4$ or $75 \mathrm{~m}$ for code $1 / 2$ runways, respectively (Annex 14, Table 4-1, ICAO, 2016). On this strip, no mobile object is permitted to be within $60 \mathrm{~m}$ for code $3 / 4$ and $45 \mathrm{~m}$ for code $1 / 2$ distance, if the runway is to be used for precision approach, and no fixed object other than visual navigation aids (Annex 14, Section 3.4.7, ICAO, 2016). Part of the runway strip must be graded and certain limits on the slope of the graded portion apply according to ICAO Doc 9157 (2006). For an instrument runway $75 \mathrm{~m}$ must be graded when the code is 3 or 4,50 $\mathrm{m}$ must be graded is the code number is 1 or 2 . In case of a non-instrument runway of code 1 , only 30 m must be graded.

An instrument runway needs to have a runway end safety area of at least $90 \mathrm{~m}$ (Annex 14, Section 3.5.2, ICAO, 2016) and width of at least twice the one of the runway (Annex 14, Section 3.5.4, ICAO, 2016). Depending on runway code and the wingspan of the aircraft intending to use the runway the runway centreline is recommended to be separated from taxiways by at least the distance given in table 3-1 of Annex 14 (Annex 14, Section 3.9.7, ICAO, 2016), reproduced below as Table 1.

The runway holding position must be at least 40 meters from the runway centerline for code $1 / 2$ and $75 \mathrm{~m}$ for code $3 / 4$ runways in order to satisfy at least the requirement for a non-precision approach runway (Annex 14, Section 3.12.6 and Table 3-2, ICAO, 2016). For a precision runway, these must be $60 \mathrm{~m}$ and $90 \mathrm{~m}$, respectively.

Moreover, there must be an minimum separation between taxiways and runways for example 168 meters for a C3 runway (all values are given in Table 3-1 of Annex 14, ICAO, 2016). If those minimum values cannot be met, an "aeronautical study [indicating] that such lower separation distances would not adversely affect safety" must be performed.

Chapter 4 of Annex 14 (ICAO, 2016) details the requirements for obstacle limitation requirements at the airport. These are different for instrument and noninstrument runways, but an obstacle penetration does not directly affect the runway classification but rather the minimum descent altitude calculated by the procedure designer. Parameters to calculate the surfaces are given in Table 4-1 of Annex 14 (ICAO, 2016). Likewise, runway lights do also not affect the classification of the runway, but rather the minimum visibility required for an instrument approach.

Table 1. Parameters to calculate the runwaysurfaces of Table 3-1 from Annex 14 (ICAO, 2016)

\begin{tabular}{|c|c|c|c|c|c|c|c|c|c|c|c|c|}
\hline \multirow[b]{3}{*}{$\begin{array}{l}\text { Code } \\
\text { letter }\end{array}$} & \multicolumn{8}{|c|}{$\begin{array}{l}\text { Distance between taxiway centre line and runway centre line } \\
\text { (metres) }\end{array}$} & \multirow{3}{*}{$\begin{array}{l}\text { Taxiway } \\
\text { centre line } \\
\text { to taxiway } \\
\text { centre line } \\
\text { (metres) }\end{array}$} & \multirow{3}{*}{$\begin{array}{l}\text { Taxiway, } \\
\text { other than } \\
\text { aircraft } \\
\text { stand } \\
\text { taxilane, } \\
\text { centre line } \\
\text { to object } \\
\text { (metres) }\end{array}$} & \multirow{3}{*}{$\begin{array}{l}\text { Aircraft } \\
\text { stand } \\
\text { taxilane } \\
\text { centre line } \\
\text { to aircraft } \\
\text { stand } \\
\text { taxilane } \\
\text { centre line } \\
\text { (metres) }\end{array}$} & \multirow{3}{*}{$\begin{array}{l}\text { Aircraft } \\
\text { stand } \\
\text { taxilane } \\
\text { centre line } \\
\text { to object } \\
\text { (metres) }\end{array}$} \\
\hline & \multicolumn{4}{|c|}{$\begin{array}{l}\text { Instrument runways Code } \\
\text { number }\end{array}$} & \multicolumn{4}{|c|}{$\begin{array}{l}\text { Non-instrument runways } \\
\text { Code number }\end{array}$} & & & & \\
\hline & 1 & 2 & 3 & 4 & 1 & 2 & 3 & 4 & & & & \\
\hline A & 82.5 & 82.5 & - & - & 37.5 & 47.5 & - & - & 23 & 15.5 & 19.5 & 12 \\
\hline B & 87 & 87 & - & - & 42 & 52 & - & - & 32 & 20 & 28.5 & 16.5 \\
\hline C & - & - & 168 & - & - & - & 93 & - & 44 & 26 & 40.5 & 22.5 \\
\hline $\mathrm{D}$ & - & - & 176 & 176 & - & - & 101 & 101 & 63 & 37 & 59.5 & 33.5 \\
\hline $\mathrm{E}$ & - & - & - & 182.5 & - & - & - & 107.5 & 76 & 43.5 & 72.5 & 40 \\
\hline $\mathrm{F}$ & - & - & - & 190 & - & - & - & 115 & 91 & 51 & 87.5 & 47.5 \\
\hline
\end{tabular}


All other information in Annex 14 (ICAO, 2016) are recommendations, which do not change any runway classification. Neither do they mandate absolute compliance, but only affect visibility requirements.

\section{Case study Payerne aerodrome}

Payerne Airport (ICAO code LSMP, Figure 1) is military airport with civil use located on the eastern side of lake Neuchatel in Switzerland. It serves the local business aviation needs on prior permission required basis when the military air traffic control unit is operating. The Swiss office of federal aviation has categorized the runway of Payerne Airport as a non-instrument runway and applied circling minima to all approach procedures as laid out in their document SI/SB-001. The runway is $2791 \mathrm{~m}$ long and $40 \mathrm{~m}$ wide and has an extremely limited strip width of only $75 \mathrm{~m}$ to both sides and a strip length of $2911 \mathrm{~m}$. There is no stopway but a clearway of $60 \mathrm{~m}$ length. The holding positions coincide with the $75 \mathrm{~m}$ strip width at the beginning of runway 23 , at the other end, the beginning of runway 05 , the holding positions are only $60 \mathrm{~m}$ from the runway centerline. Here, the taxiway centerline is in 75 meters distance from the runway centerline. This is not compliant with table 3-1 from ICAO Annex 14 (ICAO, 2016), but section 3.9.7 is again only a recommendation. Payerne Airport has CALVERT CAT 1 approach lighting on both runway ends, as well as runway edge light. On the strip itself, there are several obstacle of a military origin such as antennas and small concrete housing for arresting cables for fighter jets (Source AIP Switzerland).

According to Aneex 14 (ICAO, 2016), LSMP aerodrome could be classified as non-precision instrument runway code number 2 , if the take off run available would be artificially shortened to below $1200 \mathrm{~m}$. In this case, the remaining runway could be classified as a runway end safety area. Preferably, the landing runway would be in the western section, where the distance of the taxiway from the runway is greatest. This would mean an operational restriction for certain light aircraft types, but would enable the access to Payerne aerodrome in lower visibility conditions.

According to ICAO Doc 9157 (2006), the length definition of ICAO Annex 14 is in relation to take-off distances. There is no connection of Annex 14 distances with ICAO Doc 8168. EASA OPS defines the term "take-off run available (TORA)" as "...meaning "the length of runway that is declared available by the State of the aerodrome and suitable for the ground run of an aeroplane taking off" and "take-off distance available (TODA)" as "...the length of the take-off run available plus the length of the clearway, if provided". Using dual thresholds with one being displaced to give a 1200 meter declared distance could eliminate the non-instrument runway classification at Payerne. The concept of dual threshold operations was already tested in the frame of the HALS/DTOP concept in 2001 (Hoffmann, 2001) and could be implemented based on the lessons learned in Frankfurt. Dual threshold operations may not be compliant to the ICAO annexes, but differences from ICAO can be implemented as long as they are published in the national Aeronautical Information Publication (AIP).

\section{Case study Ouessant airfield}

Ouessant airport (LFEC, Figure 2) is located on the island of Ouessant of the French coast of Britanny about 24 nautical miles west of Brest. Quessant airport has a fully certified non precision instrument runway. The runway is 833 meters long, 24 meters wide, has low intensity Edge lights and a Precision Approach Path indicator (PAPI). It is served by two instrument approaches based on GNSS with Localizer Performance with Vertical guidance (LPV) and a $300 \mathrm{ft}$ AGL minimum as well as one Non Directional Beacon (NDB) approach. It has a strip width of $80 \mathrm{~m}$,

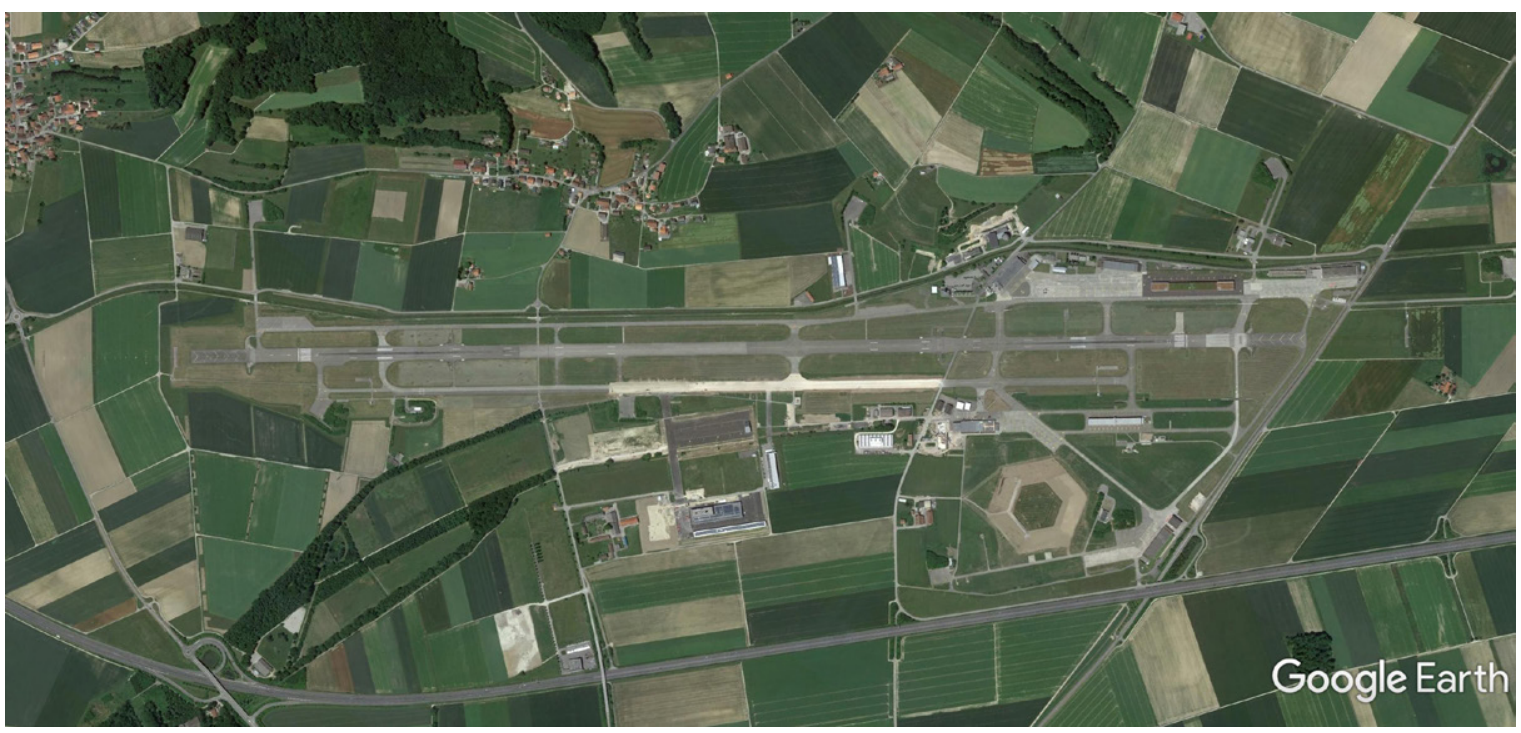

Figure 1. Aerial view of Payerne airport. The runway is classified as non-instrument. We can see the narrow width of the runway strip but also the CAT1 approach lights to either side. Arresting cables provisions are visible $450 \mathrm{~m}$ from threshold 0.5 and $750 \mathrm{~m}$ from the threshold 23. Strip width is $75 \mathrm{~m}$ 


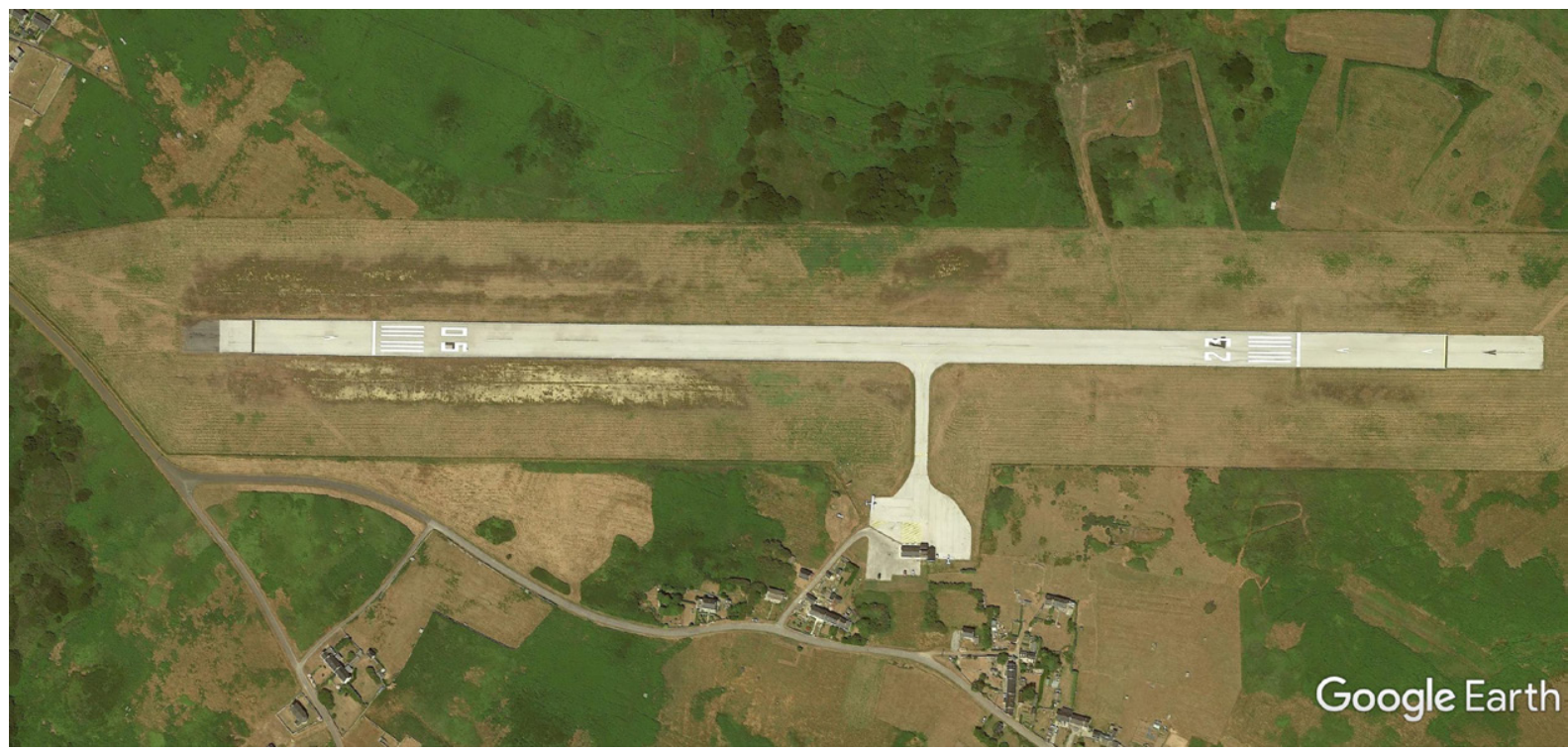

Figure 2. Aerial view of Ouessant airport. The runway is non-precision instrument runway. There is no approach light system, but low intensity edge lights and a PAPI. Strip width is $75 \mathrm{~m}$
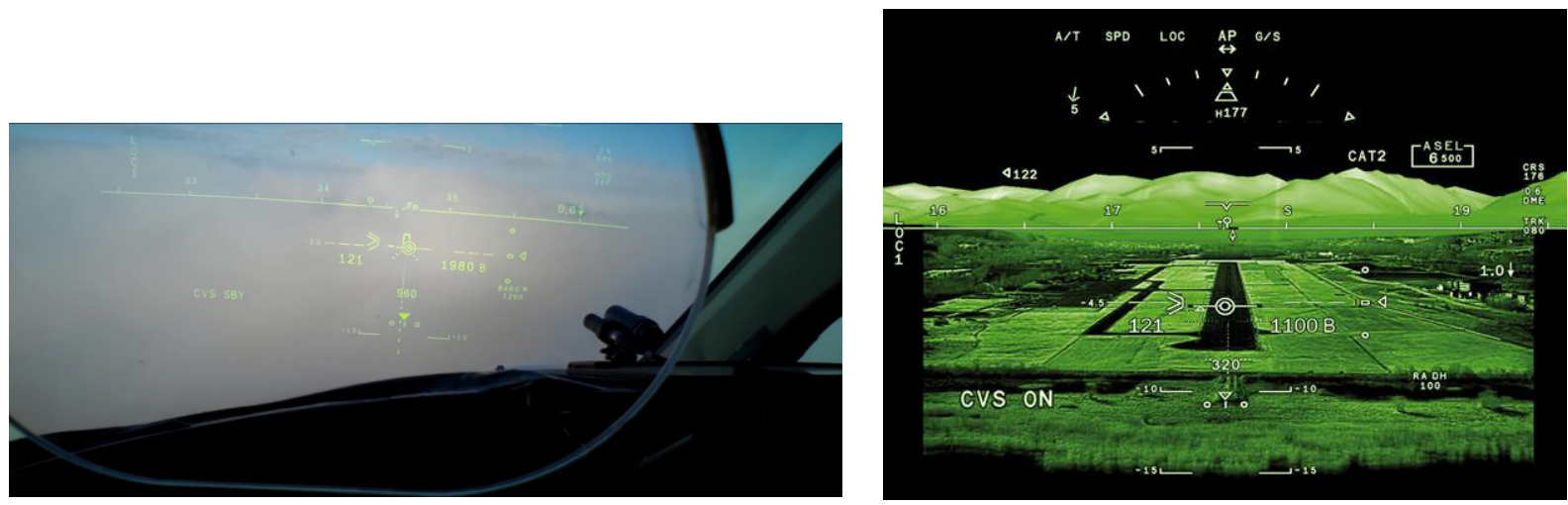

Figure 3. Dassault Falcon Eye CVS (promotional video at https://www.youtube.com/watch?v=iJ37n_O2UWE)

a stopway of $50 \mathrm{~m}$ and a clearway of $30 \mathrm{~m}$. According to Annex 14 (ICAO, 2016), this is fully sufficient to be classified as instrument runway (Source AIP France). There is small taxiway to the apron and the holding position is located $75 \mathrm{~m}$ from the runway centerline.

\section{Lowering minima for equipped aircraft and airports}

As can be seen from the above examples, the classification of non-instrument runway can vary widely from a recreational grass or gravel strip to a nearly fully equipped airport such as Payerne. Furthermore, one needs to recognize that the lowest category of instrument runways, which are suitable for non-precision approach do not require very many conditions to be fulfilled. Major impact has the runway strip width and its grading, which cannot be influenced by any other means than constructional measures. While for the common grass strip, circling minima are sufficiently low, given that no infrastructure needs to be present at the airport, non-instrument runway classifications such as Payerne suffer from reduced access, even though the available ground infrastructure is available.
The required minimum visibility for an instrument approach is strongly influenced by the availability of approach and runway lights, as is the usability of airport at night. These issues could be overcome by a suitably equipped aircraft with augmented vision.

Radio and Telecommunications Commission for Aeronautics RTCA DO359 (2015) and FAA (2017a) Advisory Circular AC20-185 detail the technical standards for a synthetic vision guidance system that can be used to descend below the published MDA. Such a system, for example, could be the Dassault Falconeye CVS head up system (see Figure 3) which allows descent to $150 \mathrm{ft}(45.72 \mathrm{~m})$ decision height and $1400 \mathrm{ft}$ (426.72 $\mathrm{m}$ ) RVR according to US CFR 91.176 and the part 135 and 121 equivalents, FAA (2017b). Advisory Circular AC90-106A Fleet equipage with these new systems, however, is still low. EASA gives the legal framework by part CAT.OP.MPA.305 and the associated acceptable means of compliance. For head down guidance, Honeywell developed Smart View (Feyereisen et al., 2015) serving the same purpose. It shows synthetic extended centerline analogue to the commonly known sequenced flashing lights, runway markers and lead in lines. 


\section{Conclusions}

Instrument approaches to non-instrument runways are possible according to the latest revision of Annex 6 of the convention of Chicago, as long as the required visibility and ceiling conforms to visual meteorogical conditions.

Many states take circling minima as the golden rule for approach operations, as they are already in place for airports that have only one runway end with instrument approach procedures. However, the spectrum on non-instrument runways varies from a simple grass strip to nearly fully equipped airport. Payerne LSMP is a textbook case of an equipped airport which has only a reduced strip width and is therefore classified as NIR. During the research for this work, we encountered various states which apply "should" and "recommendations" as mandatory rules, restricting airfields further in their possibility to classify runways as instrument ones. Moreover, political issues and disagreements between certifying agencies can lead to stalled runway recertification. For examples, airport neighbours might fear increased noise pollution due to higher traffic volumes.

In the case of Payerne, we suggest the airport to be recertified with a displaced threshold, resulting in reduced length which in turn reduces the required strip width. For example, two sets of approach charts can be published with different take-off and/or landing distances available. Then, the decision altitude on the existing approach could be lowered to the standard non precision approach minima.

In order to lower visibility minima, approach lights and runway lights need to be installed. In general, the rule is that the better the installed lighting system is, the lower the required minimum visibility can be reduced.

Besides installing expensive approach lights, an artificially generated, conformal light system with extended centerline, runway markers and lead in lights could be provided to the pilot via enhanced or augmented vision.

\section{Acknowledgements}

We would like to thank Olivier Baudson from Dassault as AAL WP3 Leader, Reviewer Andreas Lipp from Eurocontrol and Oliver Meyer from DFS for their valuable feedback in improving this manuscript.

\section{Funding}

This project has received funding from the SESAR Joint Undertaking under the European Union's Horizon 2020 research and innovation programme under grant agreement No 783112 as part of the VLSD project AAL2.

\section{Disclosure statement}

We the authors, do not have any competing financial, professional, or personal interests from other parties. Furthermore, we would like to point out that this study deals with the classification of instrument runways according to ICAO Annex 14 only. It does not concern itself with procedure design issues and any other legal considerations surrounding the imple- mentation of instrument flight procedures. Payerne and Ouessant airports already have instrument approach procedures in place and the focus is on the small gap between the decision height and visibility requirements of $600 \mathrm{~m}(250 \mathrm{ft})$ RVR and $150 \mathrm{~m}(500 \mathrm{ft}$ ) RVR between instrument runways and noninstrument runways. Furthermore, there is no obvious link between ICAO Annex 14 and ICAO Doc 8168, such that one influences the other, but then on the other hand, maybe that is the intention. The project partner Deutsche FlugSicherung (DFS) who was not involved in this study, does not support double threshold operations for the time being - if the study relates DFS to double threshold operations, mentioned DFS opinion should clearly be pointed out. DFS which is different from DLR does not support the lowering of minima below circling minima at non-instrument runways. Aerodromes under DFS jurisdiction that are aiming for lower minima should apply for IFR approval. The contents of this study has a scientific approach only and is not intended to support safety assessments, operational issues or related provisions. Objectives related to the Instrument Approach Procedure (IAP) approval process are herein not taken into account.

\section{References}

European GNSS Agency and ESSP. (2017). Instrument flight procedures for general aviation (GNSS based).

Federal Aviation Administration (FAA). (2017a). Aircraft AC 20-185 - Airworthiness Approval of Synthetic Vision Guidance System. FAA.

Federal Aviation Administration (FAA). (2017b). Air Traffic and General Operating Rules AC 90-106A - Enhanced Flight Vision Systems. FAA.

Feyereisen, T., He, G., Wyatt, S., Conner, K., \& Johnson, S. (2015). Smartview lower minimums: A synthetic vision guidance system [Conference presentation]. 2015 IEEE/AIAA 34th Digital Avionics Systems Conference (DASC), 3A2-13A2-13. https://doi.org/10.1109/DASC.2015.7311389

Hoffmann, A. (2001). Flugbetriebliche und Flugmeteorologische Grundlagen für einen Zweischwellenbetrieb von HALS/ DTOP. Deutscher Luft- und Raumfahrkongress, 2001, DGLRJT2001-84.

International Civil Aviation Organization (ICAO). (2006). Aerodrome design manual part 1 runways, Doc 9157 (3rd edition). ICAO.

International Civil Aviation Organization (ICAO). (2012a). Performance-based navigation manual, Doc9613 (4th edition). ICAO.

International Civil Aviation Organization (ICAO). (2012b, 29 June). Attachments to a State letter AN 11/1.1-12/40. file:///C:/Users/54887/Downloads/12565-Source $\% 20$ Texts-46064-1-18-20201126\%20(1).pdf

International Civil Aviation Organization (ICAO). (2014). Procedures for air navigation services aircraft operations, Doc 8168, volumes 1 and 2 (6th edition). ICAO.

International Civil Aviation Organization (ICAO). (2016). Annex 14 to the Convention of Chicago, Volume I, Aerodrome Design and Operations (7th edition, July). ICAO.

Radio and Telecommunications Commission for Aeronautics (RTCA). (2015). Minimum Aviation Systems Performance Standards for Synthetic Vision Guidance Systems, DO359.

Swiss Federal Office of Civil Aviation. (2009). Directive SI/SB001, IFR approach minimum on non-instrument runways.

United Kingdom Civil Aviation Authority. (2014). Application for instrument approach procedures to aerodromes without an instrument runway and/or approach control, CAP 1122. 